\title{
PRESCRIÇÃO DO DIA: INFUSÃO DE ALEGRIA. UTILIZANDO A ARTE COMO INSTRUMENTO NA ASSISTÊNCIA À CRIANÇA HOSPITALIZADA
}

\author{
Giovana Müler Françani* \\ Daniela Zilioli* \\ Patrícia Regina Ferreira Silva* \\ Roberta Paula de Melo Sant'ana* \\ Regina Aparecida Garcia de Lima**
}

FRANÇANI, G.M.; ZILIOLI, D.; SILVA, P.R.F.; SANT’ANA, R.P.de M.; LIMA, R.A.G.de. Prescrição do dia: infusão de alegria. Utilizando a arte como instrumento na assistência à criança hospitalizada. Rev. latinoam.enfermagem, Ribeirão Preto, v. 6, n. 5, p. 27-33, dezembro 1998.

O objetivo deste trabalho é relatar a experiência de um grupo de alunas do Curso de Graduação em Enfermagem da Escola de Enfermagem de Ribeirão Preto da Universidade de São Paulo que utiliza a arte (aspectos do teatro Clown) como recurso auxiliar da enfermagem na assistência à criança hospitalizada. Baseado no trabalho realizado pelo grupo "Doutores da Alegria" e nos conhecimentos teóricos das disciplinas de Psicologia e Enfermagem Pediátrica e Neonatal estas alunas criaram a Companhia do Riso que procura resgatar o riso da criançalfamília hospitalizada. A partir desta experiência podese observar algumas transformações no dia-a-dia: o espaço hospitalar tornou-se mais informal e descontraído, o riso pode ser ouvido com maior freqüência e objetos, sons, movimentos, cores, espaços e personagens podem se tornar brinquedos.

UNITERMOS: enfermagem pediátrica, criança hospitalizada, recreação infantil

\section{INTRODUÇÃO}

Existe uma infinidade de definições e conceitos sobre a arte. Na perspectiva dos filósofos, Platão considera-a "o esplendor do verdadeiro", Aristóteles descreve-a como "a ordem e a harmonia das partes" e para Leibniz "arte é a perfeição" apud MARINO (1966).

Não devemos ver a arte apenas como algo restrito às galerias e museus. Devemos vê-la como algo possivelmente presente no nosso cotidiano. Assim ela se encontra em tudo o que as pessoas fazem para agradar aos seus sentidos e está também intimamente ligada com o criar, trabalhar e realizar.

Entendendo que a arte não se restringe a lugares próprios, estando ela presente no nosso cotidiano, o artista não é apenas aquele que se apresenta nos palcos dos teatros ou o criador das grandes obras que se encontram nos museus e cidades históricas. O artista é caracterizado pela capacidade de criar, trabalhar e realizar ações e obras que agradem aos seus sentimentos e aos de outros, dotado de uma sensibilidade tal que saiba escolher para cada momento e população, os instrumentos específicos que satisfarão as necessidades do outro e conseqüentemente de si mesmo.

A arte é encontrada na criança quase como algo inato, verdadeiramente espontâneo, absolutamente criativo. Ela manifesta-se na maioria das vezes através das brincadeiras (FRIEDMANN, 1992; PINHEIRO \& LOPES, 1993; VIGOTSKI, 1994; LIMA, 1995).

Estudos já comprovaram a importância do brincar para o desenvolvimento sensório-motor e intelectual da criança, assim como sua importância no processo de socialização, no desenvolvimento e aperfeiçoamento da criatividade e auto-consciência. Tem também um importante papel na formulação dos valores morais. WHALEY \& WONG (1989) afirmam que “(...) brincar é um dos aspectos mais importantes na vida de uma criança e um dos instrumentos mais eficazes para diminuir o estresse".

Ao brincar a criança libera sua capacidade de criar e reinventa o mundo, libera afetividade e através do mundo mágico do "faz-de-conta" explora seus próprios

\footnotetext{
* Alunas do $7^{\circ}$ semestre do Curso de Graduação da Escola de Enfermagem de Ribeirão Preto da Universidade de São Paulo ** Orientadora. Professora Doutora Regina Aparecida Garcia de Lima, docente das disciplinas de Saúde da Criança e Enfermagem Pediátrica e Neonatal da Escola de Enfermagem de Ribeirão Preto da Universidade de São Paulo
} 
limites e parte para uma aventura que poderá levá-la ao encontro de si mesma (CUNHA, 1994).

Tratando-se de crianças hospitalizadas, o brinquedo tem também um importante valor terapêutico, influenciando no restabelecimento físico e emocional pois pode tornar o processo de hospitalização menos traumatizante e mais alegre, fornecendo melhores condições para a recuperação.

A literatura tem registrado a superioridade da abordagem por meio da dramatização quando comparada com a unicamente verbal. Através da primeira, podemos nos comunicar com as crianças, informando-as de forma mais compreensível e prepará-las para enfrentar situações novas. Através desta técnica a criança pode conhecer detalhes da vida no hospital de tal forma que vivencie a função real e não fantasiada do instrumental hospitalar e das técnicas empregadas durante a assistência. Durante a dramatização a enfermeira pode observar se as informações foram ou não assimiladas, aspecto este que, via de regra, escapa-lhe, já que as crianças não manifestam, muitas vezes, espontânea e abertamente o que estão pensando ou sentindo, e muito menos, respondem de maneira satisfatória as perguntas diretas (LIMA, 1995).

A perspectiva da utilização do brinquedo em Enfermagem Pediátrica é a de servir como meio de comunicação entre os profissionais e a criança e detectar a singularidade de cada uma. Do ponto de vista da criança ele promove o desenvolvimento físico, psicológico, social e moral; ajuda-a a perceber o que ocorre consigo, libera temores, raiva, frustração e ansiedade. Ajuda a criança, ainda, a revelar seus pensamentos e sentimentos, promovendo satisfação, diversão e espontaneidade. Assim, brincando ele exercita suas potencialidades.

Mesmo reconhecendo-se a importância do brincar para o desenvolvimento infantil, sua utilização sistemática na assistência à criança hospitalizada ainda não é realidade em muitas instituições brasileiras. No entanto, algumas experiências têm sido registradas, como a descrita a seguir.

Em 1986, Michael Christensen, diretor do Big Apple Circus de Nova Yorque, foi convidado para uma apresentação em comemoração ao Dia do Coração no Columbia Presbyterian Babies Hospital e optou por fazer uma satirização às rotinas médicas e hospitalares mais conhecidas, realizando transfusão de milk-shake e transplante de nariz vermelho entre outras, utilizando técnicas do teatro Clown (mistura de técnicas circenses e teatrais). A reação positiva do público encorajou Michael a pedir permissão para visitar as crianças que não tinham sido capazes de participar do evento, apresentando-se como o mais novo médico em um dos quatro andares da pediatria do citado hospital. O resultado surpreendeu a todos: crianças que encontravam-se deprimidas e apáticas esforçavam-se ao máximo para participar dos jogos propostos. Após outras visitas, o hospital decidiu investir na continuidade do trabalho, nascendo então a Clown Care Unit (DOUTORES, 1997).

Em 1988, Wellington Nogueira, ator brasileiro que na ocasião morava em Nova Yorque, passou a integrar a troupe da Clown Care Unit, no papel de "Dr. Calvin" e começou a dar seus plantões no Memorial Sloan Kettering Cancer Center, um dos maiores centros de pesquisas de câncer no mundo.

Em 1991, Wellington retorna ao Brasil disposto a montar aqui um programa irmão da Clown Care Unit do Big Apple Circus. Em setembro do mesmo ano, no Hospital e Maternidade Nossa Senhora de Lourdes, teve início o programa brasileiro, batizado com o nome de "Doutores da Alegria"***, que tem como principal objetivo “(...) usar o conhecimento, arte e sensibilidade para avaliar a necessidade da criança e colocar esses conhecimentos a seu dispor", utilizando-se do Teatro Clown.

Dado o interesse de um grupo de alunas do $7^{\circ}$ semestre que cursava as disciplinas Psicologia e Enfermagem Pediátrica e Neonatal no Curso de Graduação em Enfermagem da Escola de Enfermagem de Ribeirão Preto da Universidade de São Paulo (EERPUSP), realizou-se, em novembro de 1995, uma Oficina de Trabalho sobre "Assistência à criança: humanização hospitalar através da arte", ministrada pelo próprio Wellington Nogueira.

Com base no programa desenvolvido pelos "Doutores da Alegria", associado aos conhecimentos teóricos dessas disciplinas as alunas da EERP-USP orientadas pela Prof ${ }^{\mathrm{a}}$. Dra ${ }^{\mathrm{a}}$. Regina Aparecida Garcia de Lima, docente junto ao Departamento de Enfermagem Materno-Infantil e Saúde Pública criaram em 1996, a "Companhia do Riso", cujo objetivo é resgatar o riso da criança/família hospitalizada, através de atividades divertidas como: injeção de alegria, extração de mau humor e transplante de nariz vermelho. Para a escolha do nome procurou-se ter como palavra chave o riso, pois

\footnotetext{
*** Para melhor esclarecimento ver:
}

HOSPITAL E MATERNIDADE NOSSA SENHORA DE LOURDES. Doutores da Alegria: perguntas e respostas. s.n.t. 3 p. e DOUTORES da Alegria: arte e cultura num cenário inusitado. s.n.t. 8 p. Estes textos descrevem a organização e atividades desenvolvidas pelo grupo 
ele constitue nos dizeres de MENEZES (1974) um evidente sintoma de saúde física e mental, individual e coletiva.

Considerando que o ambiente hospitalar traz à criança sensações de medo frente ao tratamento e que ela geralmente não espera coisas agradáveis nesse ambiente, decidiu-se pela implantação desse trabalho na Pediatria do Hospital das Clínicas da Faculdade de Medicina de Ribeirão Preto da Universidade de São Paulo (HCRP-USP), Unidade do Campus, por considerar que a criança hospitalizada necessita de ações que possam minimizar o estresse e assim contribuir para que a hospitalização interfira o mínimo possível em seu desenvolvimento.

Assim, o objetivo desse trabalho é relatar a experiência de um grupo de alunas do $4^{\circ}$ ano do Curso de Graduação em Enfermagem da Escola de Enfermagem de Ribeirão Preto da Universidade de São Paulo que utiliza a arte como instrumento auxiliar da enfermagem na assistência à criança hospitalizada, procurando resgatar o riso e a diversão.

\section{MATERIAL E MÉTODOS}

\subsection{Local do estudo}

Este trabalho está sendo realizado no $7^{\circ}$ andar do HCRP-USP, Unidade do Campus, local reservado à Clínica Pediátrica. O hospital em questão é uma instituição de ensino, que além de prestar assistência à população, é também campo de estágio para graduandos de Medicina, Enfermagem e Psicologia; para residentes de Medicina, Psicologia e Fisioterapia e estagiários dos cursos de Auxiliar e Técnico de Enfermagem. Tem duas unidades de pediatria, uma no prédio do Campus e a outra no prédio da Unidade de Emergência. Na primeira unidade são hospitalizadas crianças com patologias crônicas e mais complexas e que geralmente são submetidas a freqüentes reinternações sendo uma das poucas onde internam crianças com câncer. $\mathrm{Na}$ Unidade de Emergência, geralmente são internadas crianças com patologias de menor complexidade e em ambas as unidades, funciona o Programa Mãe Participante****.

A unidade pediátrica do HC Campus conta com 35 leitos nos quais são internadas crianças e adolescentes até quatorze anos. $\mathrm{O}$ andar é dividido em duas alas que são denominadas A e B. Na ala A situa-se o Berçário de Alto Risco a Unidade de Terapia Intensiva Pediátrica (UTI Pediátrica), ainda não ativada e enfermaria de préescolares e escolares, com seis leitos. $\mathrm{Na}$ ala B localizamse as enfermarias 702, 704 e 706, cada uma também com seis leitos, onde são internados os lactentes e o isolamento protetor reservado para crianças imunodeprimidas, com cinco quartos. Em geral as crianças são distribuidas nas enfermarias de acordo com o tipo de patologia.

No andar há ainda um refeitório, sala de repouso para acompanhantes, com cadeiras reclináveis e aparelho de TV, sala de recreação montada com mesas e cadeiras infantis, armários e estantes com brinquedos (jogos, quebra-cabeças, bonecas, carrinhos, tintas, etc). Todas as dependências do andar, incluindo os postos de enfermagem, área dos elevadores, corredores, entre outras, têm as paredes pintadas com fundo claro e decoradas com desenhos e pinturas de motivos infantis, sendo esta característica recente e possibilitada através de uma reforma na estrutura física do andar.

\subsection{Recursos}

Foi padronizada a utilização de jaleco branco de mangas compridas. Na parte superior do mesmo encontrase a inscrição "Prescrição do dia: infusão de alegria" que foi o slogan criado pelo grupo; na frente pintura de desenhos coloridos comuns ao cotidiano das crianças (personagens de estórias em quadrinhos ou super heróis). Os cabelos são penteados em forma de tranças com armaduras de arames ou "maria-chiquinhas" e sobre eles é colocado um chapéu que varia de acordo com o clown. A paramentação é finalizada com a maquilagem característica de palhaço e a utilização do nariz vermelho.

Em cada "visita" são utilizados brinquedos de material plástico coloridos, imitando ferramentas (alicates, martelos, serrotes, chaves de fenda), miniaturas de ferros de passar, relógios, apitos e o nariz vermelho, sendo que cada criança, na primeira visita, recebe o nariz vermelho. O grupo dispõe ainda de dois martelos plásticos grandes com apitos, denominados "anestesia", e uma galinha de borracha tamanho natural que tem o nome de "Giselda". Todo o material vai para o hospital dentro de duas maletas plásticas. O grupo utiliza como recurso a comunicação através de músicas, brincadeiras infantis e perguntas diretas à criança.

Cada criança possui uma pasta chamada

**** Para melhor aprofundamento ver:

SÃO PAULO (Estado). Leis, Decretos, etc... Resolução SS - 165, 12 out. 1988. Diário Oficial do Estado, São Paulo, 14 de mar. 1989. Seção I, p. 99. Constam desta resolução as normas técnicas para implantação e desenvolvimento do programa "Mãe-Participante" e dispõe sobre sua estrutura e funcionamento, composição da equipe de saúde, população alvo, além de aspectos relativos à permanência da mãe na internação 
"Prontuário da Alegria". Nela há a identificação da criança, com nome completo, registro do hospital, idade, sexo, procedência e resumo da história clínica atual. Nesta pasta registra-se a data, o período (manhã ou tarde) o local onde a criança encontra-se (corredor, enfermaria, sala de recreação, sala de TV, cama ou cadeira de rodas) e uma breve descrição do estado geral da criança em relação ao que possa interferir no processo de brincar (soro, sonda, dreno, imobilização, cateter de oxigênio, infusão de quimioterápicos, curativo cirúrgico, repouso e jejum). São registrados, também, todos os procedimentos, materiais oferecidos e as reações da criança frente ao grupo e às brincadeiras (susto, medo, raiva, choro, risada, algumas falas relevantes, pedidos).

No hospital é feita a desinfecção, com álcool a $70 \%$, de todo o brinquedo a ser usado. Coloca-se os brinquedos na parte superior da maleta, também desinfectada e quando utilizados são guardados na divisória inferior, de modo a não manterem contato entre si. Os jalecos são submetidos a uma lavagem simples, com água corrente e sabão neutro, similar a técnica hospitalar para os aventais utilizados no isolamento. Estes são colocados em embalagens plásticas limpas e são vestidos dentro do isolamento protetor por onde sempre é iniciada a visita. Durante as brincadeiras, evita-se ao máximo o contato das crianças com o jaleco.

Decidiu-se pela chegada ao hospital já de maquilagem e chapéu, para tentar tornar habitual a figura do clown no ambiente hospitalar.

\section{DESENVOLVIMENTO DO TRABALHO}

As visitas não são programadas em horários fixos, ocorrendo, no mínimo, uma vez por semana, com duração média de três horas.

O grupo faz a paramentação no vestiário da EERP-USP. Durante o processo de maquilagem e arrumação dos cabelos, geralmente cria-se um clima de descontração e o grupo aproveita para repassar as brincadeiras e atividades a serem desenvolvidas com as crianças. É comum, enquanto no vestiário, a entrada de docentes, funcionários e alunos da Escola, que reagem sempre de maneira alegre, fazendo perguntas a respeito do trabalho e incentivando-o.

Terminada a paramentação, o grupo pega as maletas, a "Giselda" e se dirige a pé ao Hospital, que fica a mais ou menos $100 \mathrm{~m}$ da Escola. As reações pelo caminho são variadas e imprevisíveis: as crianças que estão no ponto de ônibus (que fica em frente ao portão da Escola) geralmente acenam com a mão e sorriem e os pais cuidam de chamar a atenção dos desatentos; os carros que passam quase param e do pessoal que cruza com o grupo, surgem reações diversas, tais como gargalhadas, vergonha, expressões interrogativas e a maioria dirige-se ao grupo perguntando o motivo de estar caracterizado daquela maneira. As mesmas reações seguem-se até a chegada do grupo à Clínica Pediátrica, no sétimo andar.

Ao chegar na unidade, é informada à enfermeira de plantão sobre a presença do grupo e este encaminhase preliminarmente ao isolamento protetor. Lá, após a desinfecção dos brinquedos, é feito um levantamento das crianças (nome, idade e patologia) através das papeletas.

O grupo divide-se em duplas, pois no total são quatro participantes, e distribuem-se nos quartos. Cada criança é consultada sobre a possibilidade de entrarmos e isto geralmente é feito através do acompanhante. Recebida a permissão, o grupo entra chamando a criança sempre pelo nome quando se trata de lactentes ou pelo nome de alguma personalidade, geralmente ídolos infantis, o que provoca o primeiro riso do pré escolar ou escolar..."É aqui o quarto do Batman?".

As brincadeiras variam de acordo com a idade da criança. Os lactentes são estimulados a pegarem os brinquedos coloridos, a sentarem-se, a baterem palmas acompanhando as músicas cantadas pelo grupo e nessa idade é mais comum o envolvimento dos acompanhantes nas brincadeiras, o que geralmente aumenta a confiança das crianças.

Os lactentes, em geral, costumam reagir com medo nos primeiros momentos, chegando até mesmo a chorar. O grupo insiste se percebe que há alguma receptividade e se o acompanhante estimula a criança a aceitar, mas nunca força sua presença, principalmente se o familiar nega-se a colaborar. Quando o grupo sabe da presença de alguma criança que vai assustar-se, no caso já conhecida, evita expor-se a ela. A maioria delas que reage com medo e choro na primeira visita, acostumase e passa a interessar-se pelas brincadeiras nas próximas visitas, chorando agora quando o grupo afasta-se para brincar com outra criança ou ir embora.

As crianças maiores são submetidas a estímulos diferentes, cujo principal objetivo é fazê-las rir. Nesse caso, em se tratando de uma primeira visita, o grupo começa apresentando-se como uma equipe de enfermeiras especializadas em "Besterologia" que está ali porque foi chamada para atender a um caso crônico de "tristeza profunda". É perguntado se a criança aceita a consulta e inicia-se com uma série de perguntas tais como: "Você é casado?" "Você cria galinhas?" (aproveita o momento para apresentar a "Giselda"), "O que você mais gosta de comer?", "Quando você acorda, qual a primeira coisa que faz?", "Você foi no casamento da sua mãe?", entre outras. Nesse momento o grupo aproveita 
para observar os principais anseios das crianças, incentivar a alimentação e estimular o levantar do leito. Todas as respostas são comentadas pelo grupo e é constante a presença do improviso.

É na primeira visita que é feita a grande "cirurgia" denominada "extração de mau humor", caracterizada pelo "transplante de nariz vermelho". Após alguns exames, que inclui o "teste do pezinho" (utiliza-se as ferramentas de plástico para fazer cócegas nos pés), "medição da veia cômica" (veia imaginária que "contém alegria") com uma régua plástica, o paciente é informado que se trata de um "caso cirúrgico" e perguntado se dispõe-se a fazer a cirurgia. Esta inicia-se com uma "anestesia". Para tal é utilizado o martelo vermelho e amarelo de apito, que é batido de acordo com a área não prejudicial à criança, levando-se em conta a presença de curativos ou lesões. Após a "anestesia", inicia-se o "processo cirúrgico" com a utilização das ferramentas plásticas, que recebem denominações próprias: os pentes são os "afastadores de cabelo", o serrote é o "bisturi", a chave de fenda é usada para "apertar parafuso solto" e com o alicate arranca-se o "miolo-mole-mal-posicionado" (nariz vermelho de material plástico, que disfarçadamente é colocado próximo ao local onde está sendo feita a "cirurgia") e coloca-se no nariz da criança, seguindo uma salva de palmas por parte do grupo, um sorriso emocionado do acompanhante e um ar mais alegre da criança, que quase nunca retira o novo adereço na presença do grupo. Após o transplante mede-se novamente a "veia-cômica", constatando-se uma melhora significativa ou não, o que varia de acordo com a participação da criança e termina-se fazendo a prescrição que geralmente são "exercícios respiratórios" (assoprar o apito dado pelo grupo três vezes ao dia), comer todas as refeições de horário, levantar da cama, assistir TV e dar no mínimo trinta risadas por minuto. Quando uma criança já foi submetida a uma primeira visita, apresenta-se mais animada e sorridente na próxima e participa mais ativamente das brincadeiras.

Terminada a visita no isolamento, o grupo faz nova desinfecção dos brinquedos e encaminha-se para as demais enfermarias. Geralmente os acompanhantes, sabendo da presença do grupo, ficam com suas crianças na porta da enfermaria, aguardando a saída. As brincadeiras se repetem então com cada uma, individualmente, e nesse momento é comum que elas acompanhem o grupo, participando das brincadeiras com outras crianças.

Quando alguma criança não se interessa em participar, o grupo tenta estimular. Frente à recusa da criança e à disponibilidade do acompanhante, as brincadeiras passam a ser feitas com este, que recebe os presentes, o que geralmente desperta a atenção da criança e rende muitas risadas por parte dela.

No caso das visitas acontecerem no horário do almoço ou jantar e há alguma criança alimentando-se mal, o grupo incumbe-se de participar do processo de alimentação e até hoje obteve sucesso.

Durante toda a visita, é considerada a disponibilidade física da criança para a realização das brincadeiras e nunca entra-se no quarto ou enfermaria, sem sua autorização.

O grupo conta com um vocabulário próprio, que inclui uma maneira ingênua de olhar o ambiente hospitalar. Chama sempre as infusões venosas por alguma bebida, que varia de acordo com a cor ("caipirinha" para o soro, "licor de morango" para a papa de hemáceas, "cerveja" para quimioterápicos), e o equipo de soro é sempre chamado "canudinho". Procura-se não fazer alusões ao ambiente hospitalar ou pronunciar nomes de medicamentos ou procedimentos (sangue, injeção, dipirona) no sentido exato e se usados são sempre associados aos brinquedos. É comum, nas primeiras visitas, a criança rebater dizendo que "não é caipirinha, é soro", mas algumas posturas mudam à medida que as visitas sucedem e a criança passa a enquadrar-se mais no momento de brincar e ouve-se a frase depois de um esbarrão de um clown no equipo de soro "Hei, quase que você derruba minha cerveja!!" Com a utilização desse vocabulário, o grupo tenta desviar atenção da criança dos fatores que estão provocando dor ou incômodo, fazendo com que ela ainda que por alguns minutos, seja capaz de transportar-se para um mundo de brincadeiras e fantasias.

Terminada as visitas, o grupo retorna à Escola onde são feitas as anotações nos "Prontuários da Alegria" e discute-se os casos novos e algumas alterações por parte das crianças que estão sendo visitadas a mais tempo. Aproveita o momento para planejar a próxima visita enfocando aspectos que precisam ser trabalhados com cada criança (auditivo, visual, motor, cognitivo, fala, entre outros).

Segue-se agora exemplos de duas anotações, de lactente e escolar, respectivamente:

22/05/96 (tarde) “A." estava no carrinho, com soro e sonda nasogástrica, no corredor do isolamento. Não aceitava a dieta via oral que era oferecida pela auxiliar de enfermagem. Ficou com medo e assustou-se quando nos aproximamos. Após retirarmos a máscara, iniciou um tímido contato. Sorriu pouco e bateu as mãos quando cantamos "Pirulito que bate bate". Chorou quando ouviu dizer que íamos embora (Assinatura do anotador).

04/06/96 (tarde) “A.” estava no carrinho, com sonda nasogástrica e soro, no corredor do isolamento. Sorriu imediatamente com a nossa entrada. Quando começamos a cantar "Pirulito 
que bate bate", pareceu lembrar-se e bateu as mãozinhas como na primeira visita. (Assinatura do anotador).

04/06/96 (tarde) "B." estava no quarto do isolamento, com bolsa de diálise peritoneal, em companhia do pai e da tia. Chorava muito, recusando qualquer aproximação, apesar do estímulo do pai. Não deixava seu pai sair de perto, permanecendo abraçado a ele. Ao perguntar se queria que saíssemos do quarto não respondeu, mesmo assim preferimos sair, na tentativa de que ele se acalmasse (Assinatura do anotador).

13/06/96 (tarde) "B" chegou da UTR (Unidade de Transplante Renal) acompanhado do pai e irmão quando já estávamos na enfermaria. Durante a brincadeira com as outras crianças, "B" acompanhou interessado. Quando abordado, mostrou-se receptivo. Fizemos a "coleta de dados" e ele respondeu todas as perguntas. Foi "anestesiado" em sua cabeça, apertamos alguns "parafusos soltos" e realizamos "transplante de miolo-mole-malposicionado". Fizemos também o "teste do pezinho"e ele deu muita risada. Estava muito comunicativo. O pai participou ativamente de toda a "consulta" (Assinatura do anotador).

\section{CONSIDERAÇÕES FINAIS}

A presença do Clown, expressa através da Companhia do Riso, no ambiente hospitalar abre espaço para a fantasia, o riso, a alegria... A partir desta experiência pode-se observar algumas transformações no dia-a-dia: o espaço hospitalar tornou-se mais informal e descontraído, o riso pode ser ouvido com maior freqüência e objetos, sons, movimentos, cores, espaços e personagens podem se tornar brinquedo. Identificamos aqui uma intervenção concreta que valoriza o processo de desenvolvimento infantil.

Observou-se nesses três meses de trabalho, que o ambiente hospitalar está mais acostumado à presença do clown, sendo agora comum sermos requisitadas a visitar crianças internadas em outros andares do mesmo hospital e estes pedidos são feitos pelas enfermeiras, pais que nos vêem chegar ao hospital e até mesmo os ascensoristas.

As crianças pedem sempre que o grupo permaneça mais tempo e afirmam que estarão lá em suas camas na próxima semana, mesmo quando dizemos a frase criada por Wellington: "Esperamos não encontrar você aqui na próxima semana", e na maioria das vezes são deixadas mais falantes e alegres do que quando foram encontradas.

Sendo o objetivo do grupo levar alegria a essas crianças, o trabalho continua, pois segundo WUO \& BURNIER (1996), a arte deve permanecer no sonho de todas as crianças sendo que estas não precisam de máscaras, por isso, assim como os autores “(...) utilizamos a menor máscara do mundo: o nariz de palhaço: a que menos esconde, e a que mais revela".

\section{PRESCRIPTION FOR THE DAY: INFUSION OF JOY. USING ART AS AN INSTRUMENT FOR THE CARE OF HOSPITALIZED CHILDREN}

The purpose of this study is to report on the experiment of a group of undergraduate students from the University of São Paulo at Ribeirão Preto College of Nursing, who use art (some aspects of the Clown Theatre) as a nursing resource in the care to hospitalized children. Having as basis the job performed by the group of physicians "Joy Doctors", and the theoretical grounding from Psychology and Pediatric and Neonatal Nursing, those students founded the Laugh Company that aims at rescuing laugh within the hospitalized child/family. This experiment has caused some changes in daily care: the hospital space has become more informal and relaxed, laugh can be heard more often and some items, such as, objects, sounds, movements, colours, rooms and people can become toys.

KEY WORDS: pediatric nursing, hospitalized child, children's entertainment

\section{PRESCRIPCIÓN DEL DÍA: INFUSIÓN DE ALEGRÍA, UTILIZANDO EL ARTE COMO INSTRUMENTO, EN LA ASISTENCIA AL NIÑO HOSPITALIZADO}

El objetivo de este trabajo es relatar la experiencia de un grupo de alumnos de curso de pregrado de Enfermería de la Escuela de Enfermería de Ribeirão Preto de la Universidad de San Pablo, que utiliza el arte (aspectos del teatro Clon), como recurso auxiliar de Enfermería en la asistencia al niño hospitalizado. Basado en el trabajo realizado por el grupo "Doctores de 
la alegría" y en los conocimientos teóricos de las disciplinas de Sicología y Enfermería Pediátrica y Neonatal, estas alumnas crearon la compañía de la risa, que procura rescatar la risa de los niños y su familia en el hospital. A partir de esta experiencia se puede observar algunas transformaciones en el diario vivir: El espacio hospitalario se tornó más informal y sin ambiente pesado, la risas pueden ser oídas con mayor frecuencia, sonidos, movimientos, colores, espacios y personas pueden transformarse en juguetes.

TÉRMINOS CLAVES: enfermería pediátrica, niño hospitalizado, recreación infantil

\section{REFERÊNCIAS BIBLIOGRÁFICAS}

01.CUNHA, N. H. S. Brinquedoteca: um mergulho no brincar. São Paulo: Maltese, 1994.

02. DOUTORES da alegria: música e pirueta nas enfermarias infantis. Diálogo Médico, v.12, n.1, p.10-12, 1997.

03. DOUTORES da alegria: arte e cultura num cenário inusitado. s.n.t. 8 p. /Datilografado/

04. FRIEDMANN, A. O direito de brincar: a brinquedoteca. São Paulo: Scritta/ABRINQ, 1992. p. 23-31; 125-133.

05. HOSPITAL E MATERNIDADE NOSSA SENHORA DE LOURDES. Doutores da alegria: perguntas e respostas. s.n.t. 3 p. $/$ Datilografado/.

06. LIMA, R.A.G. A enfermagem na assistência à criança com câncer. Goiânia: AB, 1995. 109p.
07. MARINO, D. Libertar a criança pela arte. A palavra. Ribeirão Preto, 1966. Suplemento Cultural, 147p.

08. MENEZES, E. D. B. O riso, o cômico e o lúdico. Revista de Cultura, v.68, n.1, p.5-15, 1974.

09. PINHEIRO, M.C.D.; LOPES, G.L. A influência do brinquedo na humanização da assistência à criança hospitalizada. Rev. Bras. Enfermagem, Brasília, v.46, n.2, p.117-131, 1993.

10. VIGOTSKI, L.S. O papel do brinquedo no desenvolvimento. In: . A formação da mente. 5 ed. São Paulo: Martins Fontes, 1994. p.123-137.

11. WHALEY, L.F.; WONG, D.L. Enfermagem pediátrica: elementos essenciais à interação efetiva. Trad. Carlos H. de Cosendey. 2. ed. Rio de Janeiro: Guanabara, 1989. p. 452-457.

12. WUO, A.E.; BURNIER, L.O. O clown no hospital. In: ENCONTRO BRASILEIRO DE PSICOONCOLOGIA, 3, São Paulo, 1996. Anais. São Paulo, 1996. p. 101-106. 